\title{
A saúde bucal coletiva na visão do estudante de odontologia - análise de uma experiência
}

\author{
Public oral health through the perspective of a dentistry student - \\ an experience analysis
}

\author{
Liliane Parreira Tannús Gontijo ${ }^{1}$ \\ M aria Cecília Puntel de Almeida ${ }^{2}$ \\ Leila Regina Scalia Gomide ${ }^{3}$ \\ Rubia Pereira Barra ${ }^{4}$
}

\footnotetext{
${ }^{1}$ FaculdadedeO dontologia, UniversidadeFederal de U berlândia. Av. Pará 1720, U muarama. 38400-902. U berlândia MG.

lili@triang.com.br

${ }^{2}$ Departamento de Enfermagem $M$ aternoInfantil eSaúdePública, Escola de Enfermagem de Ribeirão Preto, USP.

${ }^{3}$ Universidade Federal de U berlândia.

${ }^{4}$ Secretaria M unicipal de SaúdedeU berlândia.
}

\begin{abstract}
This study aims to analyze the contribution of a Pedagogical Project of Public Oral Health in the development of Dentistry undergraduate students in the perspective of the Brazilian U nified $\mathrm{H}$ ealth System principles, the promotion of oral health and the family health care, through the student's view using a social research with a qualitative approach. The project obtained an approval index of $92 \%$. The aspects that contributed the most were the actions developed during the clinical cycle followed by the primary cycle. These actions are related to the first contact with public health and social sciences aspects, showing new tendencies in the oral health/disease care process, fostering the teaching learning process to critically thinking on the dentistry in terms of the preventive perspective in relation to the appeal that current traditional curative clinical care exerts on students. This is a simple experience that has attempted to obtain positive re sponses to one of the most challenging problems for an effective implementation of the Brazilian U nified $\mathrm{H}$ ealth System which is the formation of a pre pared and sensible professionals ableto meet the population's health needs and understand the importance and impact of the socio economic, political and cultural dimensions to health care.

Key words Public oral health, Dental teaching, Family health
\end{abstract}

Resumo Este estudo analisa a contribuição de um projeto pedagógico de saúde bucal coletiva na formação do estudante do curso de graduação em odontologia, na perspectiva dos princípios do Sistema Ú nico de Saúde da promoção em saúde bucal e da atenção em saúde da família, através da visão do aluno, utilizando o enfoque da pesquisa social em abordagem qualitativa. 0 projeto obteve um índice de aprovação na ordem de $92 \%$. Os aspectos que ofereceram maiores contribuições foram atribuídos às ações desenvolvidas durante o ciclo clínico, se guido pelo ciclo básico. Constituiu-se nos primeiros contatos com aspectos da saúde col etiva e das ciências sociais, demonstrando novas ten dências no agir do processo saúde/doença bucal, criando um espaço no processo de ensino-aprendizagem de reflexão crítica sobre a odontologia, na perspectiva preventiva em relação à sedução presente na tradicional atenção clínica curativa. Representa uma experiência simples que vem tentando obter respostas positivas a um dos problemas mais desafiadores para a efetiva implementação do Sistema Ú nico de Saúde - a formação de um profissional preparado esensibilizado para atender as necessidades de saúde da população e que incorpore a importância e o impacto das dimensões sociais, econômicas, políticas e culturais para a saúde no seu agir.

Palavras-chave Saúdebucal coletiva, Ensino odontológico, Saúde da família 
Introdução

Já se constatou a existência de uma crise, um esgotamento do paradigma da saúde/doença no Brasil, crise esta que tem se manifestado em vários aspectos do processo, que envolve em especial a produção do conhecimento na área biomédica. Diante de tão séria questão, um grande desafio que se impõe àqueles que se colocam na "linha de frente" da formação dos recursos humanos, que deverão ser capazes de enfrentar não só os paradigmas e processos pedagógicos cristalizados na academia, mas ter a coragem de propor e experienciar novos métodos e práticas educacionais que contribuirão para 0 enfrentamento e transformação positiva desta que pode ser considerada a mais importante e fundamental necessidade do ser humano - a sua saúde.

Nesta perspectiva, este trabal ho analisa a contribuição de um projeto pedagógico desaúde bucal coletiva na formação do estudante do curso de graduação em odontologia, inserido em uma instituição de ensino superior privado, em U berlândia, M inas Gerais, na perspectiva dos princípios do Sistema Ú nico de Saúde da promoção em saúde bucal e da atenção em saúde da família, considerando o perfil social deste estudante.

0 referido curso de odontologia do Centro Universitário do Triângulo (UNITRI) oferece sessenta vagas semestrais, tendo iniciado sua primeira turma a partir de fevereiro de 1999.

0 projeto analisado tem como objetivo educacional formar profissionais conhecedores da realidadelocal, com postura e atitude preventiva, abertos às necessidades da população, viabilizando noções de cidadania e o estabelecimento de relações mais humanas, responsáveise comprometidoscom a resolução dos problemas sociais, em especial a saúde da comunidade, enfatizando a promoção em saúde, a saúde da família ea necessidade de articulação entreos diversos níveis de complexidadedeste setor.

Ele passou a ser aplicado, de forma interdisciplinar, a partir do primeiro ano do curso, em agosto de 1999, e se desenvolve, de forma continuada, até o 8 o período. É de autoria de quatro docentes do Centro Universitário supracitado, responsáveis pelasdisciplinas de Odontologia Coletiva, Orientação Profissional, Programa O dontológico Coletivo, Odontopediatria e Ciências Sócias aplicadas à Saúde, ejá envolveu, atésetembro de2002, cerca de 247 alunos do curso de odontologia, atendendo mais de quinhentas famílias e aproximadamente 1.300 crianças em idade escolar.

É importante salientar queo município deU berlândia está situado no extremo oeste do Estado de
M inas Gerais, na região denominada de Triângulo M ineiro, com uma população de 600.072 habitantes, segundo o censo demográfico e estimativa do $\mathrm{IBGE}^{1}$. A cidade possui uma infra-estrutura urbana considerada invejável para os padrões encontrados no país

O Sistema Único de Saúde em Uberlândia é predominantemente público e municipalizado, contando com uma ampla rede de serviços básicos em saúde, estando atualmente em gestão plena do sistema, conforme estabelecido pela N orma Operacional da Assistência ${ }^{3}$.

O Projeto Saúde Bucal Coletiva foi intitulado "SaúdeeCidadania: um projeto de integração social aluno/comunidade sob a perspectiva da atenção primária em saúde e da humanização do ensino superior" e será doravante denominado "Projeto Saúde Bucal Coletiva- Saúdee Cidadania". Elebusca integrar universidade/comunidade, ensino/pesquisa e extensão, objetivando sensibilizar e capacitar 0 aluno para incorporar um conceito ampliado de saúde, adotando uma postura preventiva para atuar em abordagens dealcance coletivo, sob a perspectiva da promoção em saúde, dos avanços da epidemiologia e da cariologia. Dentro desse enfoque, prepara também o aluno para atuar na estratégia de saúde da família, preconizada pelo M inistério da Saúde.

No momento, o projeto integra-se às unidades de saúde da rede básica do SU S eà coordenação de saúde bucal da Secretaria Municipal de Saúde de U berlândia. D efiniu-se como área de atuação dois bairros, denominados Joana D'arc e Shopping Park, e duas escolas de ensino fundamental, onde se concentram comunidades em condições sociais e econômicas desfavorecidas.

0 projeto mantém suas atividades práticas voltadas, de forma predominante, para as famílias e as crianças, no território preestabelecido, em torno da unidade de saúde da rede básica do SUS. Os estudantes de odontologia atuam em etapas previstas pelo Programa Saúde da Família (PSF), através do cadastramento das famílias com visitas domiciliares, levantamento socioeconômico, epidemiológico, assim como das condições de infra-estrutura, de equipamentos sociais e de serviços públicos no bairro eleito para o trabalho. As etapas subsequentes correspondem ao diagnóstico, análise de situação, proposta e execução de ações envolvendo a promoção, a prevenção e ações clínicas e restauradoras em saúde bucal. Uma vez que a odontologia esta incorporada na Estratégia deSaúde da Família (ESF), inserem-se os alunos em uma realidade política e sóciocultural específica da população alvo do PSF, oportunizando também a 
eles o contato com uma vertente do mercado de trabalho para os profissionais da área de saúde pública e social.

As disciplinas que dão suporteao projeto abordam os conteúdos da epidemiologia, da saúde coletiva, do planejamento em saúde e suas implicações com as políticas sociais e de saúde, analisando o papel do Estado e a formulação de sua política, assim como de suas estratégias de promoção em saúde e organização da atenção básica.

O conteúdo programático das disciplinas envolve, também, o estudo das principais doenças bucais, da programação em Odontologia Coletiva, da educação em saúde e dos métodos preventivos da cárie e da doença periodontal, a biossegurança, a ética e a postura profissional situados no contexto político, econômico e sociocultural brasileiro.

O modelo pedagógico adotado pelo Projeto Saúde Bucal Coletiva se pauta em dois conceitoschave: o primeiro é que deve se aprender fazendo, invertendo a sequência clássica teoria/prática, caracterizando que o processo do conhecimento ocorre na ordem inversa, ou seja, da prática para a teoria; e o segundo conceito traz a necessidade de aperfeiçoamento contínuo deatitudes, conhecimentos e habilidades do aluno, através de uma pedagogia de interação que privilegia o aprendizado, baseado em problemas e orientado para a comunidade e os serviços de saúde.

Outro suporte teórico que se inscreve como fundamental nesteprojeto refere-seao ideário UNI - Uma Nova Iniciativa na Educação dos Profissionais de Saúde: União com a Comunidade, construído com basenuma análise crítica das experiências anteriores de integração docente-assistencial desenvolvidas na América Latina. Esteideário, Iançado em 1991, teve como ponto de partida o contexto e o processo de construção da democracia, as principais propostas de organização dos sistemas de saúdee as idéias vigentes no movimento de mudança da educação de profissionais de saúde ${ }^{4}$.

0 projeto fundamenta-se, também, na proposta de parceria entre universidade, serviço de saúde e comunidade, em uma modalidade de cogestão do processo de trabalho colaborativo, em que os parcei ros compartilham poderes, saberes e recursos, para a construção do conhecimento.

Enfim, esteestudo objetivou caracterizar o Projeto Saúde Bucal Coletiva - Saúdee Cidadania, em sua concepção teórica e nos seus aspectos pedagógicos e operacionais, identificando as suas potencialidades e fragilidades, considerando o perfil social do estudante de odontologia e suas expectativas frente ao projeto.
Etapas do Projeto Saúde Bucal Coletiva Saúdee Cidadania

0 projeto desenvolve-se em cinco etapas, correspondentes a três anos de atividades teóricas e práticas integradas e contínuas.

a) Primeira etapa: desenvolvida durante 020 período

Participam desta etapa as disciplinas Odontologia Coletiva I/ Programa de Saúde da Família e as Ciências Sociais A plicadas à Saúde.

Coloca os alunos em contato com a realidade de uma região sócio, econômica e culturalmente desfavorecida. 0 aluno depara-se com as necessidades básicas de saúde da população, aprendendo a utilizar a rede SUS e buscar alternativas para os problemas encontrados, através do diagnóstico epidemiológico, análise de situação e elaboração de um plano de ação (Figura 1).

b) Segunda etapa: desenvolvida durante 0 3o período

Participa desta etapa a disciplina O dontologia Coletiva II, promovendo ações em saúde bucal e aplicando medidas preventivas para evitar as principais doenças bucais, atuando junto a 1.300 escolares matriculados no $1^{\circ}$ grau do ensino fundamental público das escolas estaduais do Bairro Jardim das Palmeiras e escolas municipais do Anexo Shopping Park, situadas na periferia do município deUberlândia.

0 aluno aprendea planejar e executar medidas de prevenção das principais doenças bucais para crianças em idade escolar, conforme o risco individual de adoecer. Através de encontros com os pais, esclarece sobre a situação de saúde bucal de seus filhos e orienta sobre os cuidados de promoção em saúde bucal (Figura 2).

c) Terceira etapa: desenvolvida durante o $4^{0}$ período

Participa desta etapa a disciplina O rientação Profissional I, na qual 0 aluno passa a atuar no

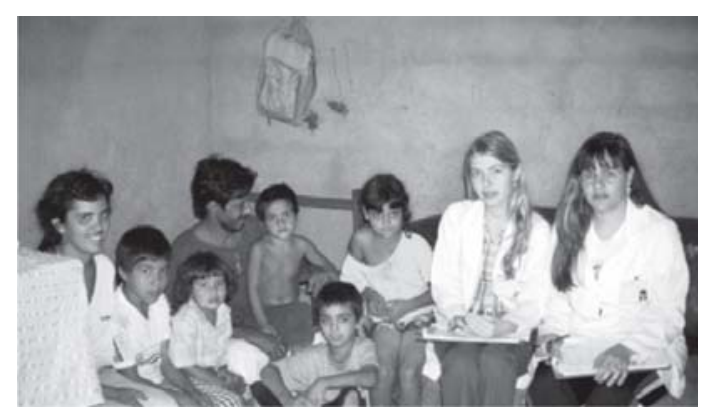

Figura 1. Estudantes de odontologia na realização da visita domiciliar e cadastramento familiar. 
domicílio dasfamílias. Promovea inserção daodontologia na visão estratégica da reorganização da atenção básica, tendo como porta de entrada o PSF, sob a perspectiva deuma prática preventiva viável econtributiva para a melhoria do perfil de morbidade das principais doenças bucais (Figura 3).

d) Quarta etapa: desenvolvida durante o 5o período

As atividades visando à saúde bucal coletiva continuam no $5^{\circ}$ período, com a disciplina Orientação Profissional II, voltada para a promoção em saúde na Creche Lar Alfredo Júlio (Figura 4).

Real izam atividades preventivas eeducativas de promoção em saúde com crianças de zero a seis anos, com as "tomadeiras de conta" da creche e com os pais destas crianças, enfatizando os preceitos da moral, dos direitos e da ética no atendimento ao ser humano.

e) Quinta etapa: desenvolvida durante os 70 e 8o períodos

Participam desta etapa as disciplinas Programa Odontológico Coletivo I ell, quando os alunosiniciam os atendimentos clínicos erestauradores, neste primeiro momento, junto às crianças em idade escolar, a partir da triagem desenvolvida pelos alu-

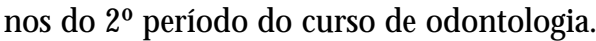

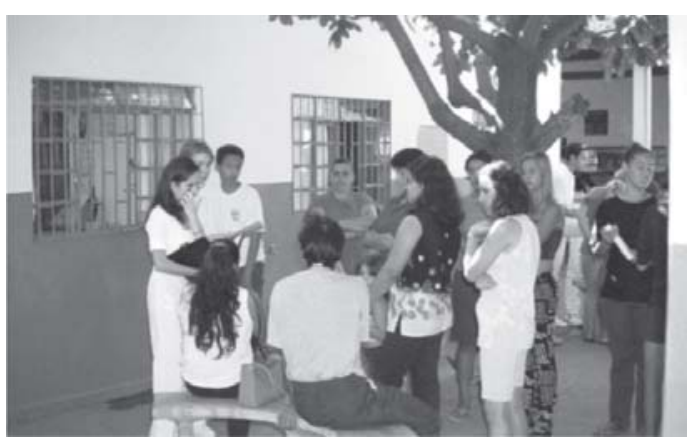

Figura 2. Estudantes de odontologia em atividades de interação com pais de alunos da E. E. Jardim das Palmeiras.

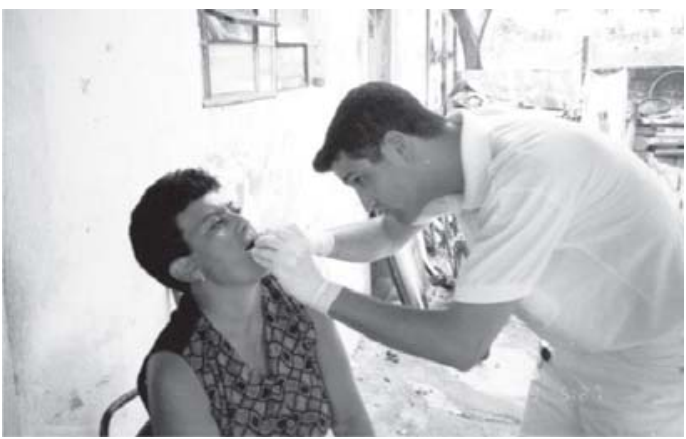

Figura 3. Estudante de odontologia realizando escovação bucal supervisionada, no domicílio.
Dando continuidade às ações desenvolvidasnos períodos anteriores, estes alunos aplicam o critério da equidade para selecionar as crianças que irão necessitar de atendimento clínico restaurador. São utilizados critérios de riscos de adoecer em relação às doenças bucais mais prevalentes, cárie e doença periodontal, possibilitando identificar parcelas da comunidade escolar e das famílias que necessitam de cuidados prioritariamente. Assim, nestes dois períodos, completa-se um ciclo de atenção preventiva e reabilitadora para as comunidades envolvidas (Figura 5 e Figura 6).

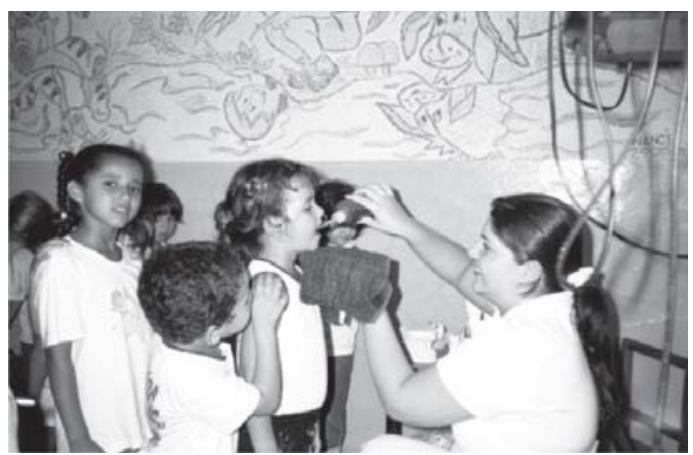

Figura 4. Estudante de odontologia realizando evidenciação de placa bacteriana com crianças da creche.

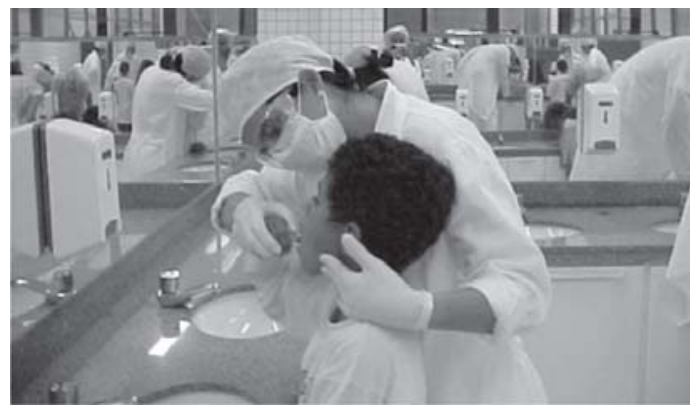

Figura 5. Estudante de odontologia realizando escovação supervisionada, antes do atendimento clínico restaurador, na Clínica da UNIT.

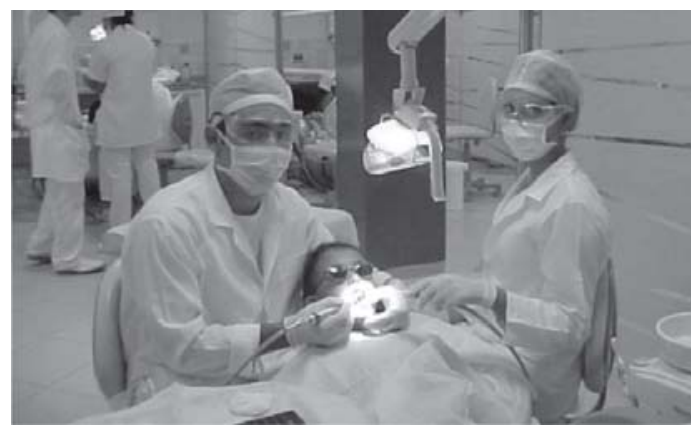

Figura 6. Estudante de odontologia realizando atendimento clínico restaurador da criança triada, com base no risco de adoecer, na clínica da UNIT. 


\section{M aterial e métodos}

Adotaram-se como instrumentos para a coleta de dados dois questionários. 0 primeiro questionário corresponde a um formulário institucional, estruturado e aplicado pelo Centro Universitário do Triângulo, que é preenchido pelo aluno, no ato da inscrição para o vestibular, através do qual se identificou o perfil sócio, econômico ecultural dos alunos que compõem a população em estudo.

0 segundo questionário, semi-aberto, foi elaborado especialmente para constatar 0 alcance dos objetivos propostos pelo presenteprojeto efoi aplicado por três auxiliares de pesquisa, sendo duas com formação em psicologia e uma em odontologia. Constituiu-se de treze questões sobre a contribuição das diferentes etapas e conteúdos programáticos do projeto, um campo aberto para sugestões, dúvidas, críticas e observações e os motivos determinantes para a escolha da carreira odontológica.

Todas as variáveis utilizadas no questionário foram qualitativas, exceto idade, tendo sido a abordagem descritiva qualitativa predominante. Após o levantamento de dados, apresentamos às variáveis por meio de frequências simples, consolidando-as em categorias analíticas.

Analisaram-se, considerando o primeiro questionário, cinquenta estudantes de odontologia e entrevistaram-se, através do segundo questionário, 51 estudantes dos 59 que preencheram, em setembro de 2002, as condições estabelecidas para participar da pesquisa - alunos que concluíram dois anos de participação do projeto, durante 0 ciclo básico, e que já tenham iniciado a sua última etapa, o ciclo clínico, referenteao 7o ou 80 períodos - correspondendo a 85\% e 86\% da população em estudo, respectivamente, e $24 \%$ dos alunos matriculados no curso de odontologia.

\section{Resultados ediscussão}

Os resultados são apresentados, inicialmente, caracterizando as variáveis que predominaram a respeito da composição do perfil social do estudante de odontologia, permitindo que se estabelecessem os parâmetros que pautaram a sua visão sobre as contribuições do Projeto Saúde Bucal Coletiva para a sua formação profissional.

Dos cinquenta estudantes que responderam 0 primeiro questionário, correspondendo a $85 \%$ da população em estudo, observou-se os seguintes resultados: $74 \%$ dos estudantes eram do sexo feminino; $52 \%$ ingressaram no curso de odontolo- gia com menos de 20 anos; $86 \%$ estavam solteiros e não tinham filhos e $74 \%$ se diziam católicos.

A respeito do nível de instrução do pai e da mãe, predominou o nível superior completo (40\%); e o segundo grau completo ( $36 \%$ ), respectivamente. Não se registrou pais de estudantes de odontologia sem nenhum estudo.

A maioria dos estudantes reside no mesmo município do Centro Universitário, em U berlândia $(66 \%)$, sendo que $88 \%$ habitam em imóvel próprio, com renda familiar entre dez a cinquenta salários mínimos (73\%).

Observamos que $78 \%$ dos alunos cursaram 0 segundo grau em escola particular, sendo queapenas $4 \%$ com bolsa e $22 \%$ em escola estadual. $74 \%$ fizeram formação geral no segundo grau. Q uanto ao curso preparatório para ingresso na universidade, $82 \%$ frequentaram curso pré-vestibular (cursinho), sendo que $40 \%$ por uma vez. $84 \%$ dos alunos já prestaram vestibular pelo menos uma vez, sendo que $44 \%$, três vezes ou mais.

Verificamos que $88 \%$ dos estudantes não exercem atividades remuneradas; $42 \%$ afirmam ler de três a cinco livros por ano (não inclui livros escolares); $40 \%$ lêem jornal ocasionalmente; $36 \%$ frequentam curso delíngua estrangeira; $25 \%$ frequentam cursos de ginástica, dança ou esportes; $25 \%$ frequentam outros tipos de cursos; $73 \%$ dos estudantes praticam algum tipo de esporte; $60 \%$ têm e manuseiam computador e $86 \%$ dos estudantes não iniciaram outro curso superior.

Quanto às expectativas em relação ao curso, observamos que $88 \%$ esperam uma formação profissional voltada para o mercado de trabalho.

0 perfil pessoal e social do estudante ingressante ao curso de odontologia da U NITRI caracterizou-se pel os seguintes aspectos marcantes: 0 ingresso em idade jovem à graduação, reproduzindo o perfil do aluno brasileiro; a feminização da profissão, como em outras áreas da saúde, deacordo com M édici ${ }^{5}$, que constatou que, entre 1970 e 1980, o contingente feminino entreos médicosaumentou de $11,6 \%$ para $20,6 \%$ e, entre os dentistas, evoluiu de $11,5 \%$ para $28,2 \%{ }^{5}$. É oriundo de classe social de maior poder aquisitivo, tendo pais com nível deescolaridade superior esegundo grau completo, o que também confirma uma pesquisa recente, que além da facilidade de acesso ao ensino privado demonstra a relação direta entre pais instruídos e quantidade de anos de escolaridade dos filhos. Assim, se o pai não estudou, o filho só fica três anos na escola. $M$ as, se o pai tiver cursado 0 ciclo elementar, ainda quesem completá-lo, o tempo de permanência do filho na escola dobra. No 
limite, filho de quem fez doutorado estuda durante quatorze anos ${ }^{6}$.

Quanto à religiosidade dos estudantes, observou-se que os resultados reproduzem em certa medida a opção da população brasileira, que apresenta $74,9 \%$ decatólicos; $13,3 \%$ deevangélicos; 3,5\% de kardecistas; $1,3 \%$ de afro-brasileiros; $2,0 \%$ de outras religiões e 4,9\% de nenhuma religião.

Estes estudantes participaram, frequentemente, de outros cursos e de atividades fora da universidade, como os de língua estrangeira e a prática esportiva e a maioria cursou o 2 o grau em escola particular, são estudantes que pertencem à classe média, possibilitando, consequentemente, várias oportunidades de crescimento pessoal e acesso cultural, incluindo-sehojea informática.

Pode-se inferir a partir dos resultados que, ao alimentarem o desejo de uma formação profissional voltada para o mercado de trabalho, justificada pelo perfil social encontrado, demonstram uma ten dência a uma visão alienada e imatura sobre as desigualdades ao acesso à saúde e da responsabilidade social da profissão escolhida.

Vale salientar que a Política Nacional de Saúde Bucal ${ }^{7}$ reconhececomo eixo das ações desaúdebucal a responsabilidade profissional e a define como: [...] implicar-se com os problemas e demandas dos usuários, garantindo respostas resolutivas, tornando-se co-responsável pelo enfrentamento dos fatores associados com o processo saúde doença em cada território. Corresponde ao desenvolvimento de práticas profissionais baseadas no respeito à identidade do usuário, conhecimento do contexto familiar e laboral, disponibilizando o tempo necessário à escuta da queixa e ao atendimento e providências pertinentes, criando suportes para a atenção integral à saúde e às necessidades dos diferentes grupos populacionais?.

Deve-se, com certeza, buscar maior engajamento social do profissional da saúde, propiciando a valorização, pelo cirurgião-dentista, da sua contribuição com a sociedade nos aspectos da saúde bucal, como um valor societário intrínseco ao profissional de saúde, que promove mudanças no comportamento mais saudável e na convivência mais adequada entre os cidadãos. Enfim, preparar um profissional cirurgião-dentista, com competência para compreensão deseu papel no mundo e na sociedade, sob a perspectiva do valor da responsabilidade social.

Em relação ao principal instrumento de coleta de dados, no segundo questionário, obtivemos opiniões de $86 \%$ dos sujeitos da pesquisa, os estudantes da primeira turma de graduandos em odontologia, sobreas questões pertinentes ao projeto, fazendo-se importante considerar que $14 \%$ dos alunos, por não terem participado da pesquisa, podem ter opiniões diferentes das informações coletadas.

Constatou-se que os principais motivos, perfazendo $60 \%$ das razões apontadas para a escolha da carreira odontológica, foram: a influência da convivênciae tradição familiar ( $32 \%$ ), seguido pelo fato de constituir-se a odontologia em uma das áreas da saúde ou das ciências biológicas (28\%).

Objetivando agrupar as causas similares, elaboramos onze categorias, apresentando os motivos em ordem decrescente de importância para a escolha da carreira odontológica, conforme apresentado na Tabela 1.

No trabalho desenvolvido por Cruz e Silva ${ }^{8}$, que identificaram os motivos determinantes para a escolha da carreira odontológica, através de pesquisa realizada com cem alunos do curso de odontologia da escola de Alfenas, encontrando como principais motivos a liberalidade da profissão, o fato do curso se dar na área biológica e o retorno financeiro. Comparando com os resultados obtidos na UNITRI, o fato da liberalidade da profissão odontológica e do retorno financeiro propiciado pela profissão não se constituírem em razões apontadas pelos estudantes de odontologia demonstra tendência de alteração frente à imagem da profissão. A influência da conjuntura econômica atual, configurando restrições à liberalidade da profissão e limitações nas possibilidades de atratividade financeira no mercado de trabal ho da área odontológica, talvez explique este resultado.

Constatamos que a justificativa predominante para indicar as contribuições do Projeto Saúde Bucal Coletiva - Saúdee Cidadania, durante todas as suas etapas, do 20 ao 8 o períodos, segundo a visão do estudante de odontologia, foi: na sua primeira etapa, identificação, integração esensibilização com a situação social, cultural, econômica e de saúde da comunidade de "baixa renda"; constituiuse no primeiro contato com aspectos da saúde pública e a sociologia; na segunda etapa, constatamos o primeiro contato prático com as necessidades das crianças de diferentes realidades e os aspectos ligados à odontologia coletiva (dentição, cárie, risco de cárie, placa, tártaro, utilização de métodos preventivos de orientação, higienização e fluorterapia, real ização de exames, diagnóstico, levantamentos epidemiológicos e avaliação em saúde); na terceira etapa, conhecimento e noção da realidade da população, reconhecimento de que a saúde bucal não é uma prioridade para as famílias, desenvolvimento de práticas preventivas, reconhecimento de casos odontológicos, despertar as famílias sobre a prevenção, proposta de ação con- 
Tabela 1. Motivos para a escolha da carreira odontológica pelos estudantes do curso de odontologia. Uberlândia, 2002.

\begin{tabular}{|c|c|c|c|}
\hline Grupo & 1.1.1.1.1.1.1 Categorias & Frequência & $\%$ \\
\hline 10 & Influência, convivência e tradição familiar/desejo de criança & 18 & 132 \\
\hline $2 \underline{0}$ & Interesse por curso na área da saúde e saúde bucal (área biológica) & 16 & 28 \\
\hline 30 & Falta de oportunidade de cursar medicina & 5 & 9 \\
\hline $4^{\circ}$ & $\begin{array}{l}\text { Experiência em áreas similares (auxiliar de consultório dentário, te'cnico em } \\
\text { prótese e técnico de higiene dental) }\end{array}$ & 4 & 7 \\
\hline 50 & Insatisfação com a área de atuação que estava cursando anteriormente & 3 & 5 \\
\hline 60 & $\begin{array}{l}\text { Interesse pelas características e habilidades pertinentes a profissão odontológica: } \\
\text { artesanal, artística, estética e minuciosa }\end{array}$ & 3 & 5 \\
\hline 70 & Interesse despertado após vivenciar a condição de paciente odontológico & 2 & 4 \\
\hline 80 & Trabalho social/Trabalho com pessoas & 2 & 4 \\
\hline 9은 & Liberalidade da profissão odontológica & 1 & 2 \\
\hline $10^{0}$ & Caráter assistencialista & 1 & 2 \\
\hline \multirow[t]{2}{*}{$11 \underline{0}$} & Desgaste em prestas cursos pré-vestibulares/N ão apresenta motivo especial & 1 & 2 \\
\hline & Total* & 56 & 100 \\
\hline
\end{tabular}

tinuada do estudante fornecendo retorno às famílias e a possibilidade de encaminhamentos desta comunidade desfavorecida; na quarta etapa, desenvolvimento de ações preventivas e aprendizagem em lidar com crianças de zero a seis anos de idade, desprivilegiadas economicamentee deatenção e carinho, percepção das dificuldades do atendimento à criança de menor idade, relacionamento com outras disciplinas e desenvolvimento de técnicas de reforço com a criança para a criação dos hábitos de higiene; a quinta e última etapa foi considerada a etapa demaior contribuição do projeto, justificado pela experiência prática da saúde bucal coletiva, voltando-se predominantemente para a intervenção clínico restauradora em contato direto com o paciente, colocação em prática do quefoi planejado, possibilitou visão ampla detodo o projeto e de vários casos odontológicos, o aluno aprendeu a lidar com o atendimento à criança de forma criativa e mais ágil, exercício da práxis - relacionamento da teoria com a prática, desenvolvimento de habilidades, autonomia de atendimento, das técnicas de dentística alternativas e conhecimento de material odontológico adequado à saúde coletiva, aprendizagem do lidar com urgências odontológicas e aplicação da odontologia sob a perspectiva da saúde pública.

O Projeto Saúde Bucal Coletiva obteve um índice de aprovação na ordem de $92 \%$, sendo que $8 \%$ de respostas consideraram que não houve nenhuma contribuição, conforme o Gráfico 1.
As justificativas predominantes para apontar as limitações do projeto, durante todas as suas etapas, corresponderam apenas a $8 \%$ das respostas fornecidas pelos alunos e podem ser sintetizados em alguns relatos pertinentes, apontando fragilidades operacionais do projeto, merecendo destaque os horários desencontrados entre estudantes efamílias a serem visitadas, limitações das ações no domicílio erepetição de ações, sugerindo a revisão destes aspectos mencionados.

\section{Síntese}

O saspectos que ofereceram maiores contribuições do Projeto Saúde Bucal Coletiva, considerados pelo estudante de odontologia, foram atribuídos às ações desenvolvidas durante o ciclo clínico. A opinião dos estudantes foi unânime ao consideraram que este ciclo do projeto proporciona o contato "profissional", levando à visão ampla das fases vivenciadas, possibilitando colocar em prática o que foi planejado, desenvolvendo habilidades inerentes à atenção clínica eintrodução dealternativas de tratamento, sob a perspectiva da saúde pública.

A segunda maior contribuição foi apontada pelos aspectos do ciclo básico, referentes ao primeiro contato do estudante com a realidade de uma comunidade socialmente excluída, demonstrando que o projeto insere o estudante de odontologia, oriundo, em sua maioria, de classes so- 


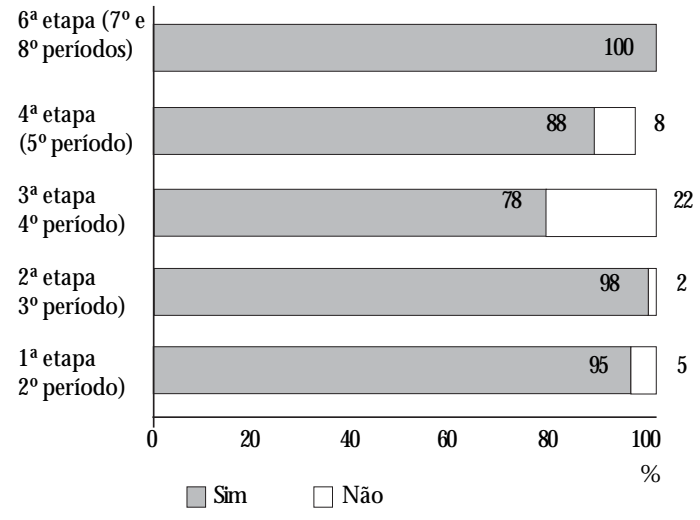

Gráfico 1. Contribuição do Projeto Saúde Bucal Coletiva para a formação do estudante de odontologia, conforme as etapas do segundo ao oitavo período. U berlândia, 2002.

ciais de maior poder aquisitivo, em uma realidade econômica, social ecultural muito diferente da que vivenciou, possibilitando o contato com uma outra vertente do mercado de trabalho, sensibilizando-o para esta realidade estranha a ele.

0 projeto constitui-se, também, nos primeiros contatos efetivos e práticos com aspectos da saúde bucal coletiva, com diferentes necessidades odontológicas de uma mesma comunidade, e com as noções de ciências sociais. Incutiu a necessidade de uma postura preventiva e socializada no agir profissional, alertando-o para a importância do SU Se da estratégia de saúde da família.

Foram relatados pelo aluno algumas fragilidadesorganizacionais eoperacionais do projeto, constituindo-se em apontamentos dignos de ajustes ao mesmo.

\section{Conclusão}

Salientamos que o Projeto Saúde Bucal Coletiva, por si só, não pode almejar a transformação das práticas e postura deste estudante, após se graduar, pois significarianão reconhecer a determinação, de pelo menos vinte anos, do convívio familiar, dos valores societaise culturais destealuno, assim como das regras desobrevivência profissional, queo próprio mercado de trabalho irá imputar-Ihe ao ini- ciar o exercício da profissão, em nosso país. Trataseainda de um projeto dentro do curso de odontologia, diferentemente da proposta UNI, por exemplo, que preconiza toda uma reestruturação curricular, em torno de proposta semelhante.

Considerando, porém, o saldo positivo encontrado nos resultados deste projeto e sua similaridade com os propósitos do UNI, seria recomendável, uma vez que se cogitasse adaptações do projeto pedagógico curricular do curso de odontologia da UNITRI, que se considerasse a positividade das experiências já implementadas em sua estrutura curricular, como a que ocorre com o Projeto Saúde Bucal Coletiva, envolvendo inicialmente as disciplinas de Odontologia Coletiva, Orientação Profissional, Programas Odontológicos Coletivos e Ciências Sociais aplicadas à Saúde. Entendemos que este projeto demonstrou coerência e conveniência para sua utilização mais ampla dentro do curso deodontologia, inclusive como já vem ocorrendo com a integração ao projeto da disciplina de odontopediatria no ciclo clínico ou o que recomendamos: 0 curso de odontologia da UNITRI implementar a reforma curricular proposta pelo Projeto UNI.

Contudo, mesmo o projeto buscando demonstrar 0 avanço da política oficial de saúde, do SUS, da estratégia de saúde da família, da epidemiologia e da cariologia e novas tendências no agir do processo saúde e doença bucal, definindo um programa de prevenção que se propõe a redimensionar 0 modelo odontológico tradicional, apesar de sensibilizar o aluno, ainda não o seduz, totalmente, como ocorre com a atenção clínica curativa, mas acaba criando um espaço no processo de ensinoaprendizagem de reflexão crítica sobre a odontologia e permite a atuação dos estudantes em saúde bucal coletiva com populações discriminadas eeconomicamente desfavorecidas.

Espera-se, assim, contribuir com uma experiência simples que vem tentando obter respostas positivas a um dos problemas mais desafiadores para a efetiva implementação do Sistema Ú nico de Saúde - a formação de um profissional preparado esensibilizado para atender as necessidades de saúde da população e que incorpore a importância e o impacto das dimensões sociais, econômicas, políticas e culturais para a saúde no seu agir. Espera-se também contribuir com uma alternativa de ensino-aprendizagem que possa ser implantada em outras universidades, neste momento em que a procura por saídas, tanto para a educação quanto para os serviços públicos de saúde no país, é urgentee necessária. 


\section{Colaboradores}

LPT Gontijo e M CP Almeida participaram igualmente de todas as etapas de elaboração do artigo; LRS Gomide e RP Barra trabalharam na concepção técnica, elaboração e redação final do texto.

\section{Referências}

1. Brasil. M inistério da Saúde. Secretaria Executiva Datasus. Tabnet. M inas Gerais. Informações em Saúde [site na Interneet]. [acessado 2000 abr 28]. Disponível em: http://www.datasus.gov.br

2. Salomão PR. 0 processo de conquista da gestão plena do sistema municipal de saúde - Uberlândia M G. Saúde \& Cidade em Debate 1999; Número inaugural:84-101.

3. Brasil. M inistério da Saúde. Portaria no 373, de 27 de fevereiro de 2002. Aprova, na forma do anexo desta Portaria, a Norma Operacional da Assistência à Saúde NOAS-SUS 01/2002. Diário Oficial da União 2002; 28 fev.

4. Almeida MJ. Educação M édica e Saúde: possibilidades de mudança. Rio de Janeiro: Editora da UEL e ABEM ; 1999.

5. Medici AC, Machado MH, Nogueira RP, Girardi SN . 0 mercado de trabalho em saúde no Brasil. Rio de Janeiro: ENSP; 1992.

6. Mendonça R. 0 paradoxo da miséria. Revista Veja 2002; 35(3):82-93.

7. Brasil. Ministério da Saúde. Departamento de Atenção Básica. Coordenação Nacional de Saúde Bucal. Diretrizes da política nacional de saúde bucal. [acessado 2005 mai 20]. Disponível em: http://portal.saude. gov.br/portal/arquivos/pdf/politica_nacional_ brasil_sorridente.pdf

8. Cruz ACS, Silva EMC. M otivos para escolha da carreira odontológica. Revista de Odontologia 1996; 10(4):315-322.

Artigo apresentado em 24/08/2006

Aprovado em 25/06/2007

Versão final apresentada em 08/08/2007 